\title{
PENERAPAN MODEL PEMBELAJARAN REFLEKTIF UNTUK MENINGKATKAN KEMAMPUAN PENALARAN MATEMATIS
}

\author{
Andi Nur Rahman ${ }^{1}$, Ilmadi ${ }^{2}$ \\ 1,2 Universitas Pamulang Tangerang \\ andi.nur.rahman@gmail.com ${ }^{1}$, il.ilmadi@yahoo.com ${ }^{2}$
}

\begin{abstract}
The purpose of this study is to describe the effect of reflective learning on mathematical reasoning abilities of mathematics students, and to analyze whether there is an interaction between reflective learning on the initial mathematical ability on mathematical reasoning abilities of mathematical students. The method used in this study is quasy experiment, in this case comparing between students who are taught by using reflective learning models with conventional learning. From the results of data analysis several conclusions can be drawn (1) Based on the results of the average similarity test where the t test value of 9.261 with the value of sig. = 0.000 smaller than $\alpha=0.05$ so that there is a significant difference between the average mathematical reasoning ability of experimental class students and the control class, therefore it is concluded that there is an influence of reflective learning models on mathematical reasoning ability of students of Mathematics and Natural Sciences Faculty of Pamulang University. (2) Based on the Anava test results $F=11,311$ with a significance of 0,000 less than $\alpha=0.05$, then rejecting $H O$ is an interaction between the reflective learning models applied to students with high, medium, and low initial ability towards students' mathematical reasoning abilities Faculty of Mathematics and Natural Sciences Pamulang University.
\end{abstract}

Keyword: Reflective Learning, Reasoning Ability, Initial Ability

\begin{abstract}
Abstrak
Tujuan dari penelitian ini adalah untuk Mendeskripsikan pengaruh pembelajaran reflektif terhadap kemampuan penalaran matematis mahasiswa matematika, serta Menganalisis ada tidaknya interaksi antara pembelajaran reflektif pada kemampuan awal matematika terhadap kemampuan penalaran matematis mahasiswa matematika. Metode yang digunakan dalam penelitian ini adalah eksperimen semu (quasy eksperiment), dalam hal ini membandingkan antara mahasiswa yang di ajar dengan menggunakan model pembelajaran reflektif dengan pembelajaran konvensional. Dari hasil analisis data dapat ditarik beberapa kesimpulan (1)Berdasarkan hasil uji kesamaan rata - rata dimana nilai uji t sebesar 9.261 dengan nilai sig. = 0.000 lebih kecil dari $\alpha=0.05$ sehingga terdapat perbedaan yang signifikan antara rata - rata kemampuan penalaran matematis mahasiswa kelas eksperimen dengan kelas kontrol, oleh karena itu disimpulkan bahwa terdapat pengaruh model pembelajaran reflektif terhadap kemampuan penalaran matematis mahasiswa program studi matematika FMIPA Universitas Pamulang. (2) Berdasarkan hasil uji Anava uji F = 11.311 dengan signifikansi sebesar 0.000 lebih kecil dari $\alpha=0.05$, maka menolak $H_{0}$ yaitu terdapat interaksi antara model pembelajaran reflektif yang diterapkan pada mahasiswa yang berkemampuan awal tinggi, sedang, dan rendah terhadap kemampuan penalaran matematis mahasiswa FMIPA Universitas Pamulang.
\end{abstract}

Kata kunci : Pembelajaran Reflektif, Kemampuan Penalaran, Kemampuan Awal

Received: December 16, 2019/Accepted: April 25, 2020 / Published Online: April 30, 2020 


\section{PENDAHULUAN}

Belajar matematika seharusnya tidak hanya terfokus pada pemahaman konsep, tetapi juga harus bisa diaplikasikan dalam kehidupan nyata dari kemampuan matematis yang ada seperti mengumpulkan, menyajikan, menganalisis serta menafsirkan data. NTCM (2003) merumuskan tujuan dari pembelajaran matematika yaitu 1) belajar untuk berkomunikasi (kemampuan komunikasi), 2) belajar untuk berfikir (kemampuan penalaran), 3) belajar memecahkan masalah (kemampuan pemecahan masalah), 4) belajar untuk mengaitkan ide (kemampuan koneksi), 5) pembentukan sikap positif terhadap matematika.

Satu diantara kemampuan matematis tersebut adalah kemampuan penalaran, Sembiring (2000) menjelaskan bahwa penalaran merupakan karakteristik utama matematika yang tidak dapat dipisahkan dari kegiatan mempelajari dan mengembangkan matematika atau menyelesaikan suatu masalah matematika. Lebih lanjut lagi Wahyudi (2008) juga menjelaskan bahwa kemampuan matematika dan berfikir bernalar secara matematis dituangkan dalam konsep - konsep sistematis dalam matematika. Kemudian konsep - konsep tersebut terus berkembang menjadi konsep yang lebih kompleks dan bahkan dapat digunakan untuk memecahkan berbagai persoalan dalam kehidupan.

Selanjutnya Wahyudi (2008) mengungkapkan bahwa kemampuan penalaran menawarkan cara - cara yang tangguh untuk membangun dan mengekspresikan ide - ide tentang beragam fenomena yang luas. Makin tinggi jenjang pendidikan seseorang, makin tinggi pula tingkat kesulitan pembelajaran matematikanya. Belajar matematika di Perguruan Tinggi terutama pada mahasiswa program studi matematika, umumnya melibatkan kemampuan berfikir tingkat tinggi, seperti kemampuan menganalisis, sintesis dan mengevaluasi, bukan hanya sekedar mengingat faktual ataupun aplikasi sederhana dari berbagai formula akan tetapi juga menerapkan aplikasi tersebut.

M.A.A. (2004) atau lebih dikenal dengan komite program sarjana matematika, memberikan 6 (enam) rekomendasi dasar untuk jurusan, program dan semua mata kuliah dalam matematika, salah satu rekomendasinya menerangkan bahwa setiap mata kuliah dalam matematika hendaknya merupakan aktivitas yang akan membantu mahasiswa dalam mengembangkan daya analisis, penalaran kritis, pemecahan masalah serta kemampuan berkomunikasi. Dari rekomendasi tersebut, terlihat bahwa kemampuan penalaran merupakan hal - hal yang perlu diperhatikan dalam pengajaran matematika khususnya di tingkat Perguruan Tinggi, tanpa mengabaikan kemampuan - kemampuan matematis yang lain. 
Jurnal Lebesgue : Jurnal Ilmiah Pendidikan Matematika, Matematika dan Statistika

Andi Nur Rahman, Ilmadi

Volume 1, No. 1, April 2020 hal.1-6

Mengingat karakteristik matematika dengan kajian yang abstrak serta bersifat deduktif, tentu bukan suatu hal yang mudah bagi seorang mahasiswa, terutama mahasiswa tingkat awal untuk mempelajari matematika. Oleh sebab itu maka dosen perlu memberikan suatu motivasi pendekatan atau model pembelajaran yang mampu mengakomodasi kemampuan berfikir atau kemampuan penalaran matematis.

Berdasarkan observasi dan tes kemampuan matematis yang diberikan kepada mahasiswa program studi matematika semester 1 (satu) menunjukkan dari 3 (tiga) kemampuan matematis yaitu kemampuan pemahaman konsep, kemampuan pemecahan masalah dan kemampuan penalaran matematis, kemampuan penalaran mendapatkan persentase yang sangat kecil, ini artinya dapat diindikasikan bahwa kemampuan penalaran matematis mahasiswa masih rendah, seperti terlihat pada tabel 1

Tabel 1.Hasil Persentase Kemampuan Matematis Mahasiswa Matematika FMIPA Universitas Pamulang Semester 1 TA 2018/2019

\begin{tabular}{clcc}
\hline No. & Kemampuan Matematis & $\begin{array}{c}\text { Menjawab Benar } \\
\text { (Dalam \%) }\end{array}$ & $\begin{array}{c}\text { Menjawab Salah } \\
\text { (Dalam \%) }\end{array}$ \\
\hline $1 \quad \begin{array}{l}\text { Soal yang menuntut kemampuan } \\
\text { pemahaman konsep }\end{array}$ & 65,0 & 35,0 \\
\hline $2 \quad \begin{array}{l}\text { Soal yang menuntut kemampuan } \\
\text { pemecahan masalah }\end{array}$ & 52,0 & 48,0 \\
\hline 3 & $\begin{array}{l}\text { Soal yang menuntut kemampuan } \\
\text { penalaran }\end{array}$ & 29,5 & 70,5 \\
\hline
\end{tabular}

Berdasarkan tabel 1 terlihat persentase mahasiswa menjawab benar soal - soal yang menuntut kemampuan penalaran hanya 29,5\%. Artinya hanya sebagian kecil dari jumlah mahasiswa matematika semester 1 yang memiliki kemampuan penalaran yang baik, oleh karena itu dosen perlu memberikan suatu inovasi supaya permasalahan ini bisa diselesaikan sehingga pada akhirnya nanti kemampuan penalaran mereka menjadi baik. Salah satu model pembelajaran yang diduga dapat meningkatkan kemampuan berfikir adalah dengan sistem pembelajaran reflektif atau Reflective Learning.

\section{METODE PENELITIAN}

Penelitian ini dikategorikan ke dalam penelitian eksperimen semu (quasi experiment). Rancangan penelitian yang digunakan dalam penelitian ini adalah Pre test Post test Control Group Design. Dalam rancangan ini terdapat dua kelompok yang dipilih secara random, 
Jurnal Lebesgue : Jurnal Ilmiah Pendidikan Matematika, Matematika dan Statistika

Andi Nur Rahman, Ilmadi

Volume 1, No. 1, April 2020 hal.1-6

kemudian diberi tes kemampuan awal (Pre Test) untuk mengetahui kemampuan prasyarat mahasiswa dalam mempelajari materi Kalkulus 1 dan untuk menentukan mahasiswa berdasarkan kategori kemampuan awal ke dalam tiga kelompok yaitu kelompok mahasiswa dengan kemampuan awal tinggi, kemampuan awal sedang dan kemampuan awal rendahPopulasi dan Sampel. Populasi dalam penelitian ini adalah seluruh mahasiswa matematika Fakultas Matematika dan Ilmu Pengetahuan Alam Universitas Pamulang Angkatan I Tahun Akademik 2018/2019.

\section{HASIL DAN PEMBAHASAN}

Berdasarkan hasil uji kesamaan rata - rata dimana nilai uji t sebesar 9.261 dengan nilai sig. $=0.000$ lebih kecil dari $\alpha=0.05$ sehingga terdapat perbedaan yang signifikan antara rata - rata kemampuan penalaran matematis mahasiswa kelas eksperimen dengan kelas kontrol, oleh karena itu disimpulkan bahwa terdapat pengaruh model pembelajaran reflektif terhadap kemampuan penalaran matematis mahasiswa program studi matematika FMIPA Universitas Pamulang.

Berdasarkan hasil uji Anava uji $\mathrm{F}=11.311$ dengan signifikansi sebesar 0.000 lebih kecil dari $\alpha=0.05$, maka menolak H0 yaitu terdapat interaksi antara model pembelajaran reflektif yang diterapkan pada mahasiswa yang berkemampuan awal tinggi, sedang, dan rendah terhadap kemampuan penalaran matematis mahasiswa FMIPA Universitas Pamulang.

\section{KESIMPULAN}

Setelah dilakukan analisis dan pembahasan diperoleh beberapa kesimpulan bahwa terdapat pengaruh model pembelajaran reflektif terhadap kemampuan penalaran matematis mahasiswa program studi matematika FMIPA Universitas Pamulang. Adanya interaksi antara model Pembelajaran reflektif yang diterapkan pada mahasiswa yang berkemampuan awal tinggi, sedang, dan rendah terhadap kemampuan penalaran matematis mahasiswa FMIPA Universitas Pamulang.

Dalam meningkatkan kemampuan penalaran matematis selain menggunakan metode pembelajaran reflektif juga dapat digunakan model pembelajaran lainnya agar dapat membandingkan model yang terbaik dalam menyampaikan materi perkuliahan.

Salah satu hasil penelitian ini adalah adanya interaksi antara model pembelajaran reflektif yang diterapkan pada mahasiswa yang berkemampuan awal tinggi, sedang, dan rendah terhadap kemampuan penalaran matematis mahasiswa FMIPA Universitas Pamulang, 
Jurnal Lebesgue : Jurnal Ilmiah Pendidikan Matematika, Matematika dan Statistika

Andi Nur Rahman, Ilmadi

Volume 1, No. 1, April 2020 hal.1-6

karena terjadi interaksi maka diperlukan analisis lebih lanjut dalam membaca efek perlakuan secara langsung dan mendetail.

\section{DAFTAR PUSTAKA}

Baroody, A.J. 1993. Problem Solving, Reasoning, and Communicating, K-8 (Helping Children Think Mathematically). New York: Macmillan Publishing Company.

Bungin, Burhan. 2013. Metodologi Penelitian Sosial dan Ekonomi. Jakarta : Prenadamedia Group, Edisi Ke-1.

Depdiknas. 2004. Peraturan Dirjen Dikdasmen No. 506/PP/2004 Tentang Perkembangan Anak Didik. Jakarta : Depdiknas.

Erman Suherman, d. 2003. Strategi Pembelajaran Matematika Kontemporer. Bandung : JICA Universitas Pendidikan Indonesia.

Fathurrohman, Muhammad. 2015. Model - Model Pembelajaran Inovatif Alternatif Desain Pembelajaran yang Menyenangkan. Yogyakarta: Ar - Ruzz Media,.

Hussin A dan Saleh. 2009. Amalan Reflektif dalam Pengajaran Matematik. Jurnal Pendidikan Islam, Jilid ke-13.

ICAJE. 2013. The International Centre For Jesuit Education in Rome. A Practical Approach (online) (p.27). Chicago: http://www.rockhurst.edu/media/filter_private/uploads/ignatian_pedagogy_a_practical_a pproach.pdf.

M.A.A. 2004. Undergraduate Program and Courses in the Mathematical Sciences. Washington DC: The Mathematics Association of America Published.

Mathematics, N. C. 2000. Principles and Standars for School Mathematics. Virginia: NCTM.

Maulana, Achmad. 2004. Kamus Ilmiah Populer. Yogyakarta: Absolut.

NCTM. 2000. Principles and Standars for School Mathematics. Reston Virginia: National Council of Teacher of Mathematics (NCTM).

Poblete, D. 1999. A Reflective Teaching Model : An Adventist Assessment. Prepare fot the 24th International Faith and Learning Held at Andrews University. Michigan, USA: Berrien Springs.

Pribadi, Benny A. 2009. Model Desain Sistem Pembelajaran. Jakarta: Dian Rakyat.

S D, D. 2006. Strategi Belajar Mengajar. Jakarta: Rineka Cipta.

Sirajuddin. 2009. Model Pembelajaran Reflektif : Suatu Model Belajar Berbasis Pengalaman. Dalam dudaktika Jurnal Pendidikan: Vol. 4 No. 2 Hal. 189 - 200.

Trianto. 2013. Mendesain Model Pembelajaran Inovatif - Progresif. Jakarta: Prenada Media. 
Jurnal Lebesgue : Jurnal Ilmiah Pendidikan Matematika, Matematika dan Statistika

Andi Nur Rahman, Ilmadi

Volume 1, No. 1, April 2020 hal.1-6

Wahyudi. 2008. Pembelajaran dan Model-Model Pembelajaran, Bandung: UPI.

Yusuf, M. 2007. Metodologi Penelitian. Padang: UNP Press. 